\title{
Síndrome da Luva Púrpura: principais intervenções preventivas e terapêuticas de enfermagem
}

\author{
Purple Glove Syndrome: main preventive and therapeutic nursing interventions
}

Sindrome del Guante Púrpura: principales intervenciones preventivas y terapéuticas de enfermería

\section{Denise Miyuki Kusahara ${ }^{1}$, Patrícia Kuerten Rocha ${ }^{2}$, Maria Angélica Sorgini Peterlini ${ }^{3}$, Mavilde da Luz Gonçalves Pedreira $^{4}$}

\section{RESUMO}

A Síndrome da Luva Púrpura, complicação relacionada à administração de fenitoína por cateteres intravenosos periféricos, caracteriza-se pelo surgimento de lesões teciduais no local de administração do fármaco, que variam de flebite à necrose local, sendo possível se identificar, nos casos mais severos, evolução para a síndrome compartimental e suas graves conseqüências. Este estudo teve por finalidade descrever a Síndrome da Luva Púrpura e os principais cuidados preventivos e terapêuticos de enfermagem. Identificaram-se 15 publicações sobre a temática, das quais incluíram-se dez artigos. Desta forma foi possível verificar as características da síndrome, bem como propor as principais intervenções de enfermagem, tanto na prevenção quanto no cuidado.

Descritores: Fenitoína/efeitos adversos; Infusões intravenosas; Enfermagem pediátrica; Cuidados de enfermagem

\begin{abstract}
The Purple Glove Syndrome, complication related to the administration of phenytoin through peripheral intravenous catheters, is characterized for the development of injuries in the site of catheter placement. Injuries range from phlebitis to local necrosis, being possible to identify in most severe cases, the development of the compartmental syndrome and its severe consequences. To describe the Purple Glove Syndrome and the main preventive and therapeutic nursing care. A literature search on the topic was conducted. This search provided enough information to characterize the purple glove syndrome as well as to identify main nursing interventions for the prevention and management of the syndrome.
\end{abstract}

Keywords: Phenytoin/adverse effects; Infusions, intravenous; Pediatric nursing; Nursing care

\section{RESUMEN}

El Síndrome del guante púrpura, complicación relacionada a la administración de fenitoína por catéteres intravenosos periféricos, se caracteriza por el surgimiento de lesiones teciduales en el lugar de la administración del fármaco, que varían de flebitis a la necrosis local, siendo posible identificarse, en los casos más severos, evolución para el síndrome compartimental y sus graves consecuencias. Este estudio tiene por finalidad describir el Síndrome del guante Púrpura y los principales cuidados preventivos y terapéuticos de enfermería. Se identificaron 15 publicaciones sobre la temática, de las cuales se incluyeron diez artículos. Fue posible verificar las características del síndrome, así como proponer las principales intervenciones de enfermería, tanto en la prevención como en el cuidado. Descriptores: Fenitoína/efectos adversos; Infusiones intravenosas; Enfermería pediátrica; Cuidados de enfermería

\footnotetext{
${ }^{1}$ Pós-graduanda do Programa de Pós-Graduação do Departamento de Enfermagem da Universidade Federal de São Paulo - UNIFESP - São Paulo (SP), Brasil. Bolsista CAPES

${ }^{2}$ Pós-graduanda do Programa de Pós-Graduação em Enfermagem na Universidade Federal de Santa Catarina - UFSC - Florianópolis (SC), Brasil.

3 Doutora em Enfermagem; Professora Adjunto, Disciplina de Enfermagem Pediátrica, Departamento de Enfermagem da Universidade Federal de São Paulo - UNIFESP - São Paulo (SP), Brasil.

${ }^{4}$ Doutora em Enfermagem; Professora Adjunto, Disciplina de Enfermagem Pediátrica, Departamento de Enfermagem da Universidade Federal de São Paulo - UNIFESP - São Paulo (SP), Brasil.
} 


\section{INTRODUÇÃO}

A Síndrome da Luva Púrpura (SLP), complicação relacionada à administração de fenitoína por cateteres intravenosos periféricos, caracteriza-se pelo surgimento de lesões teciduais no local de administração do fármaco, que variam de flebite à necrose, sendo possível identificarse, nos casos mais graves, evolução para a síndrome compartimental e suas conseqüências ${ }^{(1)}$.

A fenitoína administrada por via intravenosa (IV), fenitoína sódica, tem sido utilizada no tratamento de crises convulsivas desde 1950, quando Merriet e Putman descreveram a eficácia clínica deste derivado da hidantoína ${ }^{(2)}$. Assim como fenobarbituricos e benzodiazepínicos, permanece como um dos anticonvulsivantes, de ação prolongada, de escolha para pacientes portadores de crises convulsivas tônico-clônicas e submetidos a procedimentos neurocirúrgicos ${ }^{(3-4)}$.

Caracteriza-se como um fármaco insolúvel em água e, a fim de promover solubilidade para a infusão IV, utilizase propileno-glicol, etanol e hidróxido de sódio como solventes para estabilizar a mistura, compondo solução com potencial hidrogeniônico extremamente alcalino $(\mathrm{pH}$ $12)^{(3)}$.

Este estudo teve por finalidade descrever a SLP e os principais cuidados preventivos e intervenções de enfermagem. Identificaram-se 15 publicações na base de dados MEDLINE, SCIELO e LILACS sobre a temática. Os critérios de inclusão empregados foram idioma e abordagem clínica da síndrome. Destaca-se que foram excluídos cinco estudos, sendo dois no idioma alemão, dois no japonês e um estudo referente a fármaco economia. Nenhuma publicação nacional foi localizada nas bases de dados consultadas.

\section{ETIOLOGIA, INCIDÊNCIA E SINAIS CLÍNICOS DA SLP}

A SLP é caracterizada por lesões dos tecidos moles, eminentemente em membros superiores, região das mãos e antebraço, que ocorrem após a administração IV de fenitoína, com ou sem a presença de extravasamento, e cuja prevalência varia entre 3\% e 7\%(5-6).

Várias hipóteses etiológicas são encontradas na literatura, sendo mais aceita a proposição relativa à extrema alcalinidade da fenitoína, característica que induziria resposta vasoconstritora local e quebra de junções intercelulares endoteliais. Este rompimento permitiria que a fenitoína extravasasse da veia atingindo os tecidos próximos ao local de inserção do cateter IV ${ }^{(7-8)}$.

A fragilidade dos sistemas vascular e tegumentar, que induz a ocorrência de extravasamentos, é fator predisponente ou de risco. A incapacidade do paciente de relatar dor no sítio de administração do fármaco, quer pela idade ou condição clínica, o local de inserção e o diâmetro do cateter IV, como também a velocidade de infusão do medicamento $(>25 \mathrm{mg} / \mathrm{min})$ têm sido descritos como fatores de risco ${ }^{(3,6)}$.

A insolubilidade da fenitoína também poderia relacionar-se ao aparecimento da SLP, por constituir fator predisponente para a formação de precipitados, ocasionando depósito de cristais na parede dos vasos e formação de fístulas, pelas quais o fármaco atingiria os tecidos adjacentes. O surgimento de fissuras na íntima do vaso, mesmo que microscópicas, quer seja pela presença destes precipitados, técnica de inserção do cateter ou desenvolvimento de flebite mecânica, igualmente poderiam permitir o extravasamento de pequena quantidade de fenitoína ${ }^{(8)}$.

Ressalta-se que alguns pesquisadores consideram o propileno-glicol, solvente utilizado para estabilizar a fenitoína, capaz de predispor à síndrome, por possuir alta osmolaridade e ser irritante aos tecidos conectivos, musculares e neuronais ${ }^{(3,5-5)}$.

Edema, descoloração da pele e dor são os sinais iniciais da SLP. O surgimento do edema tem relação com aumento da pressão osmótica intersticial, pois cerca de $70 \%$ a $95 \%$ da fenitoína é carreada por proteínas, promovendo a troca de fluídos entre os compartimentos intra e extravasculares, e propiciando o desenvolvimento de edema localizado que, ao progredir, compromete a perfusão local. Em casos graves, o edema impede o fluxo arterial, ocasionando síndrome compartimental caracterizada por pulsos filiformes, pele fria e perfusão tecidual diminuída $a^{(5-6)}$.

A descoloração da pele varia de um eritema leve no sítio de inserção do cateter, para vermelho escuro a púrpura, em uma área ampliada do membro acometido. Este fato precede o desenvolvimento de necrose tissular. Inicialmente, a dor pode ser mínima, no entanto, progressivamente, de acordo com a evolução da lesão, tende a intensificar. ${ }^{(5-6)}$

Pode-se dividir a SLP em três estágios: aparecimento, progressão e resolução (APR). A primeira evidência de lesão ocorre 2 a 12 horas após a administração da dose inicial de fenitoína, com o surgimento de edema brando e coloração de pele azul pálido ou púrpura escura. A inspeção do membro acometido pode revelar petéquias nas extremidades digitais e região palmar. Caso ocorra extravasamento os sinais são mais intensos. A dor local pode estar presente, independentemente da presença de extravasamento ${ }^{(9)}$.

A fase de progressão da SLP torna-se evidente 12 a 24 horas após a administração, quando os achados clínicos são mais intensos e a alteração da cor da pele, até então localizada, começa a se estender para as superfícies laterais das extremidades digitais do membro. Flebite e cordão fibroso no trajeto do vaso podem aparecer antes de 24 
horas $^{(1,5-6) \cdot}$ Neste estágio, complicações sistêmicas, como sepse ou instabilidade hemodinâmica, podem reduzir o fluxo sanguíneo periférico e comprometer ainda mais a perfusão local, requerendo a realização de fasciotomia ${ }^{(5-6)}$.

A fase de resolução geralmente ocorre entre duas a quatro semanas, sendo caracterizada pelo retorno gradual da coloração tegumentar, redução do edema e alívio da dor, que pode ainda persistir por semanas a meses, dependendo da extensão da lesão e sensibilidade individual do paciente $\mathrm{p}^{(5-6,9)}$.

\section{CUIDADOS PREVENTIVOS E INTERVEN-} ÇÕES DE ENFERMAGEM

Os cuidados de enfermagem para a prevenção da SLP são baseados no reconhecimento dos fatores de risco, presentes eminentemente na população pediátrica e geriátrica. A escolha apropriada do local de infusão da fenitoína IV é a primeira alternativa para a prevenção, promovendo a administração do fármaco em veias calibrosas, de fácil visualização, com fluxo sanguíneo regular e que permitam a inserção de um cateter com o maior diâmetro possível ${ }^{(5-6)}$.

A fim de promover a inspeção apropriada e freqüente do local de instalação do cateter IV, recomenda-se utilizar curativos transparentes semipermeáveis, e para prevenir eventos adversos, o uso de tala é recomendado em crianças e pacientes com alteração do nível de consciência.

Para adultos, a velocidade de administração IV não deve exceder $50 \mathrm{mg} / \mathrm{min}$ devido ao risco de instabilidade cardiovascular e depressão do sistema nervoso central. No entanto, para diminuir a prevalência da SLP recomenda-se infusão entre 20 a $25 \mathrm{mg} / \mathrm{min}$. Para crianças a velocidade de infusão varia de 1 a $3 \mathrm{mg} / \mathrm{kg} / \mathrm{min}^{(9)}$.

Os métodos de administração devem ser bem estabelecidos. Recomenda-se a infusão direta lenta ou pelo injetor lateral do equipo de infusão; contra-indica-se o uso de bombas de infusão que empregam altas pressões de administração, devendo-se utilizar as que permitem o controle de pressão distal, que deve ser mantida próxima à pressão sistólica do paciente ${ }^{(5-6)}$.

Recomenda-se interromper todas as infusões antes de administrar a fenitoína, realizar a lavagem do cateter com cloreto de sódio a $0,9 \%$ em água $(\mathrm{NaCl} 0,9 \%)$, antes ou após a infusão, além da utilização de filtros de linha de 0,22 micra, devido a baixa solubilidade e tendência a precipitação ${ }^{(4-5)}$. A diluição da fenitoína, quando se fizer necessária, deve ser realizada com $\mathrm{NaCl} 0,9 \%$ na proporção de $1 \mathrm{mg} / \mathrm{ml}$, o que lhe confere uma estabilidade máxima de duas horas. Destaca-se que as soluções bacteriostáticas de $\mathrm{NaCl}$ 0,9\% devem ser evitadas, uma vez que a presença do álcool benzílico pode causar precipitação da fenitoína(3).

A observação meticulosa do local de infusão constitui um dos métodos mais eficazes para a prevenção da SLP. Sinais de irritação vascular, dor, edema e alteração da cor da pele requerem imediata interrupção da infusão e remoção do cateter para prevenir ou limitar a lesão tissular ${ }^{(10)}$. $\mathrm{Na}$ vigência da síndrome, as intervenções de enfermagem devem objetivar a redução da lesão ao tecido atingido e a avaliação neurovascular meticulosa, que inclui aspectos relacionados á coloração da pele, gradiente térmico e alteração nas características dos pulsos periféricos.

As intervenções incluem ainda a realização de curativos apropriados ao tipo de lesão, a manutenção da temperatura local, o posicionamento do membro acometido que permita adequada perfusão tecidual e retorno venoso, a implementação de movimentos ativos e passivos das extremidades, além da redução da dor e a promoção de conforto do paciente ${ }^{(1,5)}$.

Devido a gravidade da SLP e a falta de investigações, principalmente na literatura nacional, faz-se necessária a realização de pesquisas adicionais, a fim de fornecer evidencias para a prática e garantir a segurança do paciente.

\section{REFERÊNCIAS}

1. Appleton RE, Gill A. Adverse events associated with intravenous phenytoin in children: a prospective study. Seizure. 2003; 12(6):369-72.

2. Glazko AJ. Discovery of phenytoin. Ther Drug Monit. 1986; 8(4):490-7.

3. Edwards JJ, Bosek V. Extravasation injury of the upper extremity by intravenous phenytoin. Anesth Analg. 2002; 94 (3): 672-3; table of contents.

4. Burneo JG, Anandan JV, Barkley GL. A prospective study of the incidence of the purple glove syndrome. Epilepsia. 2001; 42(9): 1156-9.

5. Hanna DR. Purple glove syndrome: a complication of intravenous phenytoin. J Neurosci Nurs. 1992; 24(6): 3405.

6. Snelson C, Dieckman B. Recognizing and managing purple glove syndrome. Crit Care Nurse. 2000; 20(3): 54-61.

7. O'Brien TJ, Meara FM, Matthews H, Vajda FJ. Prospective study of local cutaneous reactions in patients receiving IV phenytoin. Neurology. 2001; 57(8): 1508-10.

8. O’Brien TJ, Cascino GD, So EL, Hanna DR. Incidence and clinical consequence of purple glove syndrome in patients receiving intravenous phenytoin. Neurology. 1998; 51(4): 1034-9.

9. Burneo de las Casas J, Barkley G. Síndrome del guante morado. Rev Neurol. 2000; 31(4): 400.

10. Sonohata M, Asami A, Tsunoda K, Hotokebuchi T. Purple glove syndrome associated with intravenous phenytoin administration in a patient with severe mental and motor retardation. J Orthop Sci. 2006; 11(4):409-11. 